\title{
Differential effects of dopamine blockers on the acquisition of schedule-induced drinking and deprivation-induced drinking
}

\author{
JOSEPH H. PORTER, PETER A. GOLDSMITH, JAMES J. McDONOUGH, \\ GREGORY F. HEATH, and DAVID N. JOHNSON \\ Virginia Commonwealth University, Richmond, Virginia
}

\begin{abstract}
In Experiment 1, the dopamine blockers pimozide $(0.5$ and $1.0 \mathrm{mg} / \mathrm{kg})$ and spiperone $(0.062$ and $0.125 \mathrm{mg} / \mathrm{kg}$ ) suppressed the acquisition of schedule-induced drinking (a form of nonhomeostatic drinking) in rats over a 15-day chronic dosing regimen. In Experiment 2, however, the same doses of pimozide and spiperone did not affect deprivation-induced drinking (a form of homeostatic drinking) or ad-lib drinking. These data suggest that an intact dopamine system is necessary for the development of schedule-induced drinking, and that this suppression of schedule-induced drinking was not due to a general suppression of drinking per se.
\end{abstract}

Homeostatic drinking has been defined as drinking that occurs in response to changes in the cellular or extracellular fluid compartments, whereas nonhomeostatic drinking has been defined as drinking that is insensitive to imbalances in the cellular or extracellular fluid compartments (Kissileff, 1973). Extensive research has revealed much about the neuropharmacological mechanisms that influence or regulate homeostatic forms of drinking. For example, cholinergic stimulation with acetycholine (ACh) or carbachol in the lateral hypothalamus produces rapid and prolonged (30-40-min) drinking in rats (Grossman, 1960,1962 ), and this cholinergic-induced drinking appears to involve muscarinic receptors (Stein \& Seifter, 1962). Also, central stimulation of $\alpha$-adrenergic receptors inhibits drinking in rats, and this effect can be blocked by $\alpha$-adrenergic antagonists (Leibowitz, 1975a, 1975b, 1981). The role of central dopaminergic (DA) systems in the regulation of homeostatic drinking, however, remains less clear. Although lesions of the dopaminergic nigrostriatal bundle produce adipsia, they also produce aphagia and a general impairment in sensory-motor functions (e.g., Marshal, Richardson, \& Teitelbaum, 1974). Thus, the adipsia may be secondary to the general disrupting effects of such lesions, rather than to a specific effect on drinking (see Rolls \& Rolls, 1982). Central administration of dopamine produces only slight increases in drinking, but blockade of dopamine receptors with haloperidol has been reported to attenuate drinking induced by angiotensin or water deprivation, but not drinking induced by carbachol or cellular dehydration (Rolls

These data were presented at the 1983 meeting of the Society of Neuroscience in Boston, MA. Experiment 1 represents a portion of a thesis by P. A. Goldsmith in partial fulfillment of the requirements for the master's degree at Virginia Commonwealth University. Reprint requests should be sent to Joseph H. Porter, Department of Psychology, Virginia Commonwealth University, Richmond, VA 23284.
\& Rolls, 1982; Setler, 1973). Rolls and Rolls (1982) contend that the dopamine system is more related to the initiation and control of movements, rather than to the specific control of drinking behavior per se.

Recently, Robbins and Koob (1980) found that 6hydroxydopamine (6-OHDA) lesions of DA terminals in the nucleus accumbens septi attenuated the acquisition of schedule-induced drinking (a form of nonhomeostatic drinking; see Falk, 1969, 1971; Kissileff, 1973), but had no effect on deprivation-induced drinking (a form of homeostatic drinking). Unlike lesions in the nigrostriatal dopamine systems, lesions of DA terminals of the mesolimbic dopamine system (in the nucleus accumbens septi and olfactory tubercle) apparently do not produce any primary motivational deficits in eating and drinking behavior (Koob, Riley, Smith, \& Robbins, 1978). This selective disruption of schedule-induced drinking (Robbins \& Koob, 1980) is interesting in that it suggests that distinct neural mechanisms may be involved in the control of these two distinct types of drinking.

Several studies have shown that anticholinergic drugs suppress schedule-induced drinking (Burks \& Fisher, 1970; Carlisle, 1973; Sanger, 1976); however, the reduced drinking may be an indirect result of a suppression of the operant generator schedule. In the study by Carlisle (1973), variable-interval responding was partially suppressed by intrahypothalamically administered atropine with a concomitant reduction in drinking. The other studies (Burks \& Fisher, 1970; Sanger, 1976) used response-independent fixed-time food schedules, so that no independent assessment of the anticholinergic drugs' effects on the generator schedule could be made. Intrahypothalamic administration of norepinephrine produces no changes in schedule-induced drinking (Singer, Armstrong, \& Wayner, 1975), suggesting that adrenergic systems may not play a role in the regulation of scheduleinduced drinking. Other studies have examined the effects 
of DA blockers on schedule-induced drinking and have reported a suppression in drinking behavior. However, the specificity of these results for schedule-induced drinking is questionable, since two of these studies also reported a decrease in operant responding (Canon \& Lippa, 1977; Keehn, Coulson, \& Klieb, 1976) and another study (Keehn \& Riusech, 1977) used a response-independent fixed-time food schedule.

In the present experiments, we report that the DA blockers pimozide and spiperone (Joyce, 1983; Seeman, 1981) differentially affect schedule-induced and deprivation-induced drinking. Experiment 1 examined the effects of pimozide and spiperone on the acquisition of schedule-induced drinking in rats that were barpressing on a fixed-interval food reinforcement schedule. In Experiment 2 , the effects of pimozide and spiperone on water-deprivation-induced drinking and ad-lib home-cage drinking were examined.

\section{EXPERIMENT 1}

\section{Method}

Animals. The subjects were 35 adult male Holtzman albino rats (Charles River Breeders, Wilmington, MA). Each rat was housed individually in an animal colony room, and all rats were maintained on a 14-h-light/10-h-dark cycle (8:00 a.m./10:00 p.m.). Water was available ad lib in the home cages, and access to food (Purina Rat Chow) was restricted to maintain the rats at $80 \%$ body weight throughout the study.

Apparatus. The five test chambers were standard BRS/LVE operant conditioning chambers (Model SEC-002). The food tray was centered on the intelligence panel $2 \mathrm{~cm}$ above the grid floor. The response lever was located on the intelligence panel $28 \mathrm{~cm}$ to the left of the food tray and $16 \mathrm{~cm}$ above the grid floor. Water was available from a water bottle mounted outside of the chamber immediately behind the intelligence panel. The rats had access to the water bottle via a drinking tube located $28 \mathrm{~cm}$ to the right of the food tray and $16 \mathrm{~cm}$ above the grid floor. All test chambers were located in sound-attenuated cubicles. White masking noise and a $28-\mathrm{V}$ dc houselight were provided. Standard electromechanical recording and programming equipment were located in an adjoining room. Noyes food pellets $(45 \mathrm{mg})$ served as reinforcers during test sessions.

Drugs. Pimozide (Jansen Pharmaceutica) was administered ip in a $0.5 \%$ methylcellulose vehicle solution. The concentrations of the pimozide solutions were 0.5 and $1.0 \mathrm{mg} / \mathrm{ml}$. Spiperone (Jansen Pharmaceutica) was administered ip in a $0.5 \%$ methylcellulose vehicle solution. The concentrations of the spiperone solutions were 0.062 and $0.125 \mathrm{mg} / \mathrm{ml}$.

Procedure. Daily test sessions (conducted between 3:00 p.m. and 10:00 p.m.) lasted $30 \mathrm{~min}$. For the first five sessions, 30 pellets were placed in the food tray. No other food pellets were delivered during these massed-feeding baseline sessions. With the water bottle available, the rats were put into the test chamber for $30 \mathrm{~min}$. This allowed baseline water intakes to be determined (amount of water consumed in response to 30 pellets given at the beginning of the session). Throughout this study, a constant value of $1.5 \mathrm{ml}$ of water was subtracted from total session water intake for each rat to correct for water spillage due to handling of the bottles and to evaporation.

The rats were matched on massed-feeding baseline water intakes and assigned randomly to one of five groups: (1) a group of seven rats given a $0.5-\mathrm{mg} / \mathrm{kg}$ dose of pimozide; (2) a group of seven rats given a $1.0-\mathrm{mg} / \mathrm{kg}$ dose of pimozide; (3) a group of seven rats given a $0.62-\mathrm{mg} / \mathrm{kg}$ dose of spiperone; (4) a group of seven rats given a $0.125-\mathrm{mg} / \mathrm{kg}$ dose of spiperone; and (5) a vehicle control group of seven rats that received an equal volume of the vehicle solution ( $0.5 \%$ methylcelluiose) rather than drug.

After the baseline data were collected, the water bottles were removed from the test chambers and all rats were first magazine trained, and then shaped to barpress on a fixed-interval 1-sec (FI 1$s e c)$ schedule of reinforcement. Once performance was stable on the FI 1-sec schedule, it was changed to a FI 15-sec schedule and gradually increased to a FI 1-min schedule. The rats were allowed to respond on the FI 1 -min schedule for 2 days to ensure reliable responding. Then the water bottles were reintroduced in the operant chambers and the chronic drug dosing regimen was begun. All injections were given $1 / \mathrm{h}$ prior to testing. Total water intakes, number of licks, and number of barpresses were recorded for each animal. There was a total of 15 experimental sessions on the FI 1$\min$ food schedule with daily drug injections.

\section{Results}

For purposes of data analysis, mean session water intakes (in milliliters) and mean barpresses (responses per minute) were calculated from the last three sessions of the 15-day chronic dosing regimen. These data are shown in Figure 1 for each group. A one-way analysis of variance (ANOVA) was performed separately for each dependent measure. For drinking, the ANOVA was significant $[\mathrm{F}(4,30)=36.54, \mathrm{p}<.001]$. Post hoc comparisons with a Tukey test revealed that all four drug-injection groups drank significantly less $(p<.01)$ water than did the vehicle control group. There were no significant differences in water intakes between the drug-injection groups. Thus, only the vehicle control group developed schedule-induced polydipsia over the 15 days of testing on the FI 1-min food reinforcement schedule. This group consumed over five times more water (mean intake =

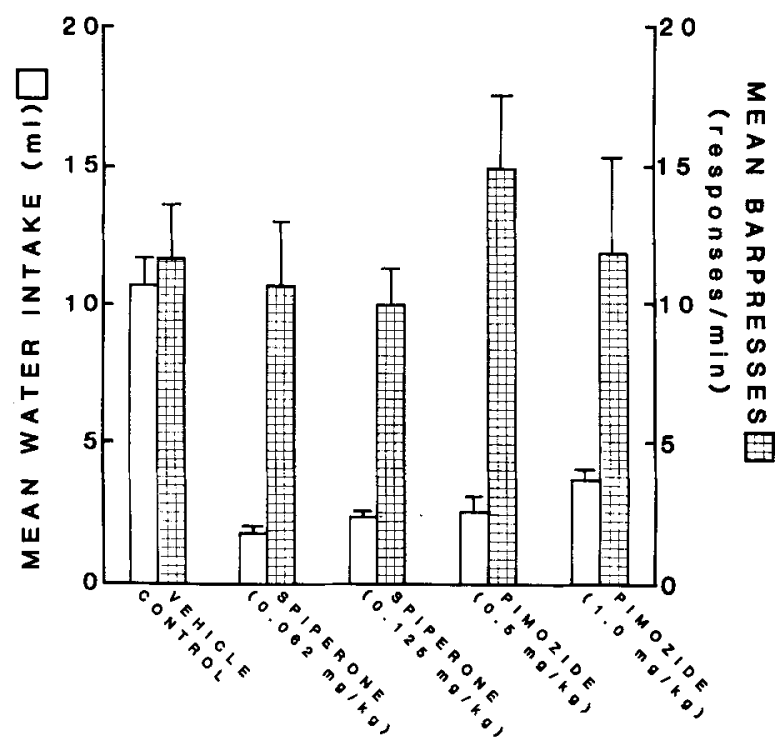

Figure 1. Mean water intakes (in milliliters) and mean barpresses (responses per minute) for the last three test sessions for each drug treatment group in Experiment 1. Plus one standard error of the mean (SEM) is indicated by the vertical bars. 
Table 1

Licks per Milliliter for the Last Three Sessions for Each Drug Treatment in Experiment 1

\begin{tabular}{lccccc}
\hline & Vehicle & Spiperone & Spiperone & Pimozide & Pimozide \\
& Control & $0.062 \mathrm{mg} / \mathrm{kg}$ & $0.125 \mathrm{mg} / \mathrm{kg}$ & $0.5 \mathrm{mg} / \mathrm{kg}$ & $1.0 \mathrm{mg} / \mathrm{kg}$ \\
\hline Mean & 68.1 & 73.4 & 78.2 & 77.2 & 86.7 \\
SE & 4.1 & 2.5 & 5.1 & 11.7 & 5.6 \\
\hline
\end{tabular}

$10.8 \mathrm{ml}$ ) during the FI schedule than during the massed feeding baseline (mean intake $=2.0 \mathrm{ml}$ ). The combined mean water intake during the massed feeding baseline for the four drug-injection groups was $2.4 \mathrm{ml}$; during the FI schedule, the combined mean intake for these groups was $2.6 \mathrm{ml}$.

The ANOVA for barpressing revealed that there were no significant differences between any of the groups $[F(4,30)=0.11$, n.s.]. Thus, at the dose of spiperone and pimozide tested, there were no significant reductions in barpressing for food on a FI 1-min schedule.

In order to determine whether or not the decreased drinking seen in the drug-injection groups was due to a motor deficit in licking, a measure of licking efficiency was computed by dividing the mean number of licks by the mean milliliters of water intake for each subject for the last three test sessions. This yielded mean licks per milliliter for each group, as presented in Table 1. An ANOVA revealed that there were no significant differences between any of the groups $[\mathrm{F}(4,30)=1.11$, n.s. $]$. Thus, there was no evidence of any motor deficit in licking ability as measured by licks per milliliter.

\section{EXPERIMENT 2}

\footnotetext{
Method

Animals and Apparatus. The subjects were 24 adult male Holtzman albino rats (Charles River Breeders, Wilmington, MA). Each rat was housed individually in an animal colony room with a 14 - $h$ light/10-h-dark cycle (8:00 a.m./10:00 p.m.). All testing was conducted in the home cages $(25 \times 20 \times 18 \mathrm{~cm})$ with food and water available as described in the procedure section.

Procedure. The rats were assigned randomly to one of three groups ( $\mathrm{N}=8$ per group). The water-deprivation (WD) group was adapted to a 23.5-h water-deprivation schedule for a period of 55 days with free access to food. The water-deprivation/food deprivation (WD-FD) group was adapted to a 23.5 -h water-deprivation schedule, but also was reduced to $80 \%$ of the free-feeding body weights by restricting their daily ration of food. The rats in the WDFD group were reduced to $80 \%$ body weight in order to equate them with the body-wieght level of the rats in Experiment 1 . The WD-FD group was maintained on this combined water-deprivation and food-deprivation and food-deprivation schedule for 55 days. The ad-lib group was maintained on ad-lib food and water during this 55-day period.

Using a latin square design, the rats then received ip injections of vehicle $(0.5 \%)$ methylcellulose), $0.062 \mathrm{mg} / \mathrm{kg}$ spiperone, $0.125 \mathrm{mg} / \mathrm{kg}$ spiperone, $0.5 \mathrm{mg} / \mathrm{kg}$ pimozide, and $1.0 \mathrm{mg} / \mathrm{kg}$ pimozide. Drug injections were given every 4 th day. The WD and WD-FD groups received the ip injections $1 \mathrm{~h}$ before the $1 / 2-h$ period of access to water. The ad-lib group received the injections at 4 p.m. on drug-injections days, and water intake was measured for the next $24 \mathrm{~h}$. All water-intake measures (milliliters) were corrected for spillage.
}

\section{Results}

Separate one-way ANOVAs on water-intake measures (see Table 2) were performed for each experimental group. No significant differences in water intakes were found for the WD group $[F(4,28)=0.11$, n.s. $]$, the WDFD group $[F(4,28)=0.27$, n.s. $]$, or the ad-lib group $[F(4,28)=0.51$, n.s. $]$. Thus, spiperone and pimozide had no effect on any of the water-intake measures.

\section{GENERAL DISCUSSION}

In Experiment 1, the acquisition of schedule-induced drinking (a form of nonhomeostatic drinking) was blocked by pimozine and spiperone. In Experiment 2, however, these same doses of pimozide and spiperone did not affect water-deprivation-induced drinking (a form of homeostatic drinking) in the WD and WD-FD groups or ad-lib drinking in the ad-lib group. These findings parallel those of Robbins and Koob (1980), who reported that 6OHDA lesions of DA terminals in the nucleus accumbens septi blocked the acquisition of schedule-induced drinking, but had no effect on water-deprivation-induced drinking.

The selective suppression of schedule-induced drinking by DA blockers in the present study differs from previous findings (Canon \& Lippa, 1977; Keehn et al., 1976) in that there was no reduction in barpressing on the foodreinforcement schedule. This is an important consideration in any research on schedule-induced drinking. As Falk $(1969,1971)$ has demonstrated, schedule-induced drinking is dependent upon several factors, including intermittent delivery of food pellets, and an adequate level of food deprivation. These minimum conditions must be met before the food schedule will generate or maintain schedule-induced drinking. Any physiological or pharmacological manipulation that causes a reduction in barpressing may also cause a reduction in the drinking behavior. However, the reduction in drinking under these conditions is probably a result of changes in the antecedent motivational conditions (i.e., food deprivation, intermittent delivery of food, reinforcement efficacy of the

Table 2

Mean Home Cage Water Intakes (Milliliters) for the WD, WD-FD, and Ad-Lib Groups Under Various Drug Injection Conditions in Experiment 2

\begin{tabular}{|c|c|c|c|c|c|}
\hline & \multicolumn{5}{|c|}{ Drug Injection Conditions } \\
\hline & Vehicle & $\begin{array}{c}\text { Spiperone } \\
0.062 \mathrm{mg} / \mathrm{kg}\end{array}$ & $\begin{array}{c}\text { Spiperone } \\
0.125 \mathrm{mg} / \mathrm{kg}\end{array}$ & $\begin{array}{c}\text { Pimozide } \\
0.5 \mathrm{mg} / \mathrm{kg}\end{array}$ & $\begin{array}{l}\text { Pimozide } \\
1.0 \mathrm{mg} / \mathrm{kg} \\
\end{array}$ \\
\hline \multicolumn{6}{|c|}{ WD Group $(\mathrm{N}=8)$} \\
\hline Mean & 25.2 & 25.9 & 26.4 & 25.1 & 26.5 \\
\hline $\mathrm{SE}$ & 2.3 & 3.0 & 2.6 & 3.5 & 2.2 \\
\hline \multicolumn{6}{|c|}{ WD-FD Group $(N=8)$} \\
\hline Mean & 59.7 & 57.5 & 55.2 & 56.9 & 53.4 \\
\hline SE & 8.4 & 5.8 & 6.0 & 7.6 & 4.8 \\
\hline \multicolumn{6}{|c|}{ Ad-Lib Group $(\mathrm{N}=8)$} \\
\hline Mean & 44.5 & 41.8 & 38.4 & 38.7 & 39.0 \\
\hline SE & 4.8 & 3.6 & 4.2 & 4.3 & 7.0 \\
\hline
\end{tabular}


food) necessary for the production of schedule-induced drinking, rather than an effect on drinking behavior per se.

Another important finding in the present study was that the suppression of schedule-induced drinking was not the result of a suppression of drinking behavior in general. As Experiment 2 demonstrated, the same doses of spiperone and pimozide which blocked the acquisition scheduleinduced drinking did not suppress water-deprivationinduced drinking or ad-lib drinking. Although other studies have reported attenuation of water-deprivationinduced drinking with DA blockers (Nielson \& Lyon, 1973; Rowland \& Engle, 1977; Setler, 1973), these studies differed procedurally from the present study. In the present study, the rats were adapted to the waterdeprivation schedule for a total of 55 days before any drug testing began. In the other studies, the animals were not adapted to a deprivation schedule, but instead were simply water deprived for $24 \mathrm{~h}$ prior to drug testing. Also, although Setler (1973) reported reliable suppression of deprivation-induced drinking with central administration of haloperidol, systemic administration (as in the present study) only partially depressed drinking in response to deprivation. Setler also stated that the antidipsogenic effect of systemic haloperidol injection could not be distinguished from a general depressant effect, which was evidenced by sedation. In the present study, there was no evidence of sedation following pimozide or spiperone injections in either Experiment 1 or Experiment 2.

In Experiment 1, pimozide and spiperone blocked the acquisition of schedule-induced drinking, but had no effect on the food-reinforced operant leverpressing. It has long been known that drugs that block DA receptors interfere with operant responding in rats and other laboratory animals (Dews \& Morse, 1961), yet no such effect was evident in the present study. This lack of effect may be due to the use of a 1-h injection time prior to test sessions, since pimozide and spiperone have typically been shown to have a peak effect on many behaviors at about $4 \mathrm{~h}$ after injection (Janssen, Niemegeers, \& Schellekens, 1965; Janssen et al., 1968). However, this conclusion is weakened somewhat by the fact that pimozide has a long half-life in rats of about $48 \mathrm{~h}$ (Pinder et al., 1976), and that the rats in Experiment 1 were receiving daily injections over the 15 days of testing. Also, the problems of chronic versus acute dosing procedures needs to be examined more closely in future research, since a chronic dosing regimen was used in Experiment 1 with scheduleinduced drinking and an acute dosing regimen was used in Experiment 2 with deprivation-induced and ad-lib drinking.

Another contributing factor to the lack of suppression of leverpressing may be that the rats were engaged in both a schedule-controlled behavior (i.e., leverpressing) and a schedule-induced behavior (i.e., drinking). Previous operant studies with such DA blockers as pimozide and spiperone have almost always allowed the animals to engage in only a single behavior. Also, most of these studies have utilized a continuous reinforcement schedule instead of an intermittent reinforcement schedule, as was used in Experiment 1 (see Wise, 1982).

The results of the present study and the study by Robbins and Koob (1980) demonstrate that an intact dopamine system is necessary for the acquisition of scheduleinduced drinking (a form of nonhomeostatic drinking). Future studies, however, will need to examine the effects of dopamine blockers both on the acquisition of scheduleinduced drinking and on established schedule-induced drinking to clearly determine the role of dopamine systems in schedule-induced drinking. The need for an intact dopamine system is further supported by the finding that d-amphetamine (which is a DA agonist) also blocks the acquisition of schedule-induced drinking (Yoburn \& Glusman, 1982). Thus, an overactive or underactive DA system interferes with the acquisition of schedule-induced drinking. While it remains to be determined if all nonhomeostatic behaviors are dependent upon an intact DA system, it has been shown by Antelman, Szechtman, Chin, and Fisher (1975) that tail-pinch-induced eating also is blocked by pimozide and spiperone. Tail-pinch-induced eating clearly differs from deprivation-induced eating and probably can be classified as a nonhomeostatic behavior.

\section{REFERENCES}

Antelman, S. M., Szechtman, H., Chin, P., \& Fisher, A. E. (1975). Tail pinch induced eating, gnawing and licking behavior in rats: Dependence on the nigrostriatal dopamine system. Brain Research, 19, 319-337.

Burks, C. D., \& Fisher, A. E. (1970). Anticholinergic blockade of schedule-induced polydipsia. Physiology \& Behavior, 5, 635-640.

CANON, J. G., \& LiPPA, A. S. (1977). Effects of clozapine, chlorpromazine and diazepam upon adjunctive and schedule controlled behaviors. Pharmacology, Biochemistry and Behavior, 6, 581-587.

CARLISLE, H. J. (1973). Schedule-induced polysipsia: Blockade by intrahypothalamic atropine. Physiology \& Behavior, 11, 139-143.

DEws, P. B., \& MoRse, W. H. (1961). Behavioral pharmacology. Annual Review of Pharmacology, 1, 145-174.

FALK, J. L. (1969). Conditions producing psychogenic polydipsia in animals. Annals of the New York Academy of Sciences, 157, 569-593.

FALK, J .L. (1971). The nature and determinants of adjunctive behavior. Physiology \& Behavior, 6, 577-588

Grossman, S. P. (1960). Eating or drinking in satiated rats elicited by adrenergic or cholinergic stimulation, respectively, of the lateral hypothalamus. Science, 132, 301-302.

GrossmaN, S. P. (1962). Direct adrenergic and cholinergic stimulation of hypothalamic mechanisms. American Journal of Physiology, 202, 872-882.

Janssen, P. A. J., Neimegeers, C. J. E., \& Schellekens, K. H. L. (1965) Is it possible to predict the clinical effects of neuroleptic drugs (major tranquilizers) from animal data? Part I: " Neuroleptic activity spectra" for rats. Arzneimittel-Forschung, 15, 104-117.

J ANSSEN, P. A. J., Neimegeers, C. J. E., Schellekens, K .H. L., Dresse, A., Lenaerts, F. M., Pinchard, A., Schaper, W. K. A., Van Neuten, J. M., \& Verbruggen, F. J. (1968). Pimozide, a chemically novel, highly potent and orally longacting neuroleptic drug. Part I: The comparative pharmacology of pimozide, haloperidol, and chlorpromazine. Arzneimittel-Forschung, 18, 261-279.

Joyce, J. N. (1983). Multiple dopamine receptors and behaviors. Neuroscience and Biobehavioral Reviews, 7, 227-256.

KeEHN, J, D., Coulson, G. E., \& KLIEB, J. (1976). Effects of haloperidol on schedule-induced polydipsia. Journal of the Experimental Analysis of Behavior, 25, 105-112. 
Keehn, J. D., \& Riusech, R. (1977). Schedule-induced water and saccharin polydipsia under haloperidol. Bulletin of the Psychonomic Society, 9, 413-415.

KissilefF, H. R. (1973). Nonhomeostatic controls of drinking. In A. N. Epstein, H. R. Kissileff, \& E. Stellar (Eds.), The neuropsychology of thirst: New findings and advances in concepts (pp. 163-198). New York: Wiley.

Kоoв, G. F., Riley, S. J., Smith, S. C., \& Robbins, T. W. (1978). Effects of 6-hydroxydopamine lesions of the nucleus accumbens septi and olfactory tubercle on feeding, locomotor activity, and amphetamine anorexia in the rat. Journal of Comparative and Physiological Psychology, 92, 917-927.

Leibowitz, S. F. (1975a). Ingestion in the satiated rat: Role of alpha and beta receptors in mediating effects of hypothalamic adrenergic stimulation. Physiology \& Behavior, 14, 745-754.

LElBowITZ, S. F. (1975b). Pattern of drinking and feeding produced by hypothalamic norepinephrine injection in the satiated rat. Physiology \& Behavior, 14, 731-742.

LEIBOwITZ, S F. (1981). Neurochemical systems of the hypothalamus in control of feeding and drinking behavior and water-electrolyte excretion. In P. J. Morgane \& J. Panksepp (Eds.), Handbook of the hypothalamus (Vol. 3, Part A, pp. 299-437). New York: Dekker.

Marshall, J. F., Richardson, J. S., \& Teitelbaum, P. (1974). Nigrostriatal bundle damage and the lateral hypothalamic syndrome. Journal of Comparative and Physiological Psychology, 87, 808-830.

NIELSEN, E. B., \& LYON, M. (1973). Drinking behavior and brain dopamine: Antagonistic effect of two neuroleptic drugs (pimozide and spiramide) upon amphetamine- or apomorphine-induced hypodipsia. Psychopharmacologia, 33, 299-308.

Pinder, R. M., Brogden, R. N., Sawyer, P. R., Speight, T. M., SPENCER, R., \& Avery, G. S. (1976). Pimozide: A review of its pharmacological properties and therapeutic uses in psychiatry. Drugs, 12 , $1-40$.
Robbins, T. W., \& Коов, G. F. (1980). Selective disruption of displacement behavior by lesions of the mesolimbic dopamine system. Nature, 285, 409-412.

Rolls, B. J., \& Rolls, E. T. (1982). Thirst. Cambridge: Cambridge University Press.

Rowland, N., \& ENGle, D. J. (1977). Feeding and drinking interactions after acute butyrophenone administration. Pharmacology, Biochemistry and Behavior, 7, 295-301.

SAnger, D. J. (1976). Scopolamine and adjunctive drinking in rats. Psychopharmacology, 48, 307-309.

Seeman, P. (1981). Brain dopamine receptors. Pharmacological Reviews, 32, 229-313.

SeTler, P. E. (1973). The role of catecholamines in thirst. In A. N. Epstein, H. R. Kissileff, \& E. Stellar (Eds.), The neuropsychology of thirst: New findings and advances in concepts (pp. 279-291). New York: Wiley.

Singer, G., Armstrong, S., \& Wayner, M. J. (1975). Effects of norepinephrine applied to the lateral hypothalamus on schedule induced polydipsia. Pharmacology, Biochemistry and Behavior, 3, 869-872.

Stein, L., \& SeIfTer, J. (1962). Muscarinic synapses in the hypothalamus. American Journal of Physiology, 202, 751-756.

WISE, R. A. (1982). Neuroleptics and operant behavior: The anhedonia hypothesis. Behavioral and Brain Sciences, 5, 39-87.

YoburN, B. C., \& GluSMan, M. (1982). Effects of chronic damphetamine on the maintenance and acquisition of schedule-induced polydipsia in rats. Physiology \& Behavior, 28, 807-818.

(Manuscript received April 16, 1984; revision accepted for publication February 15, 1985.) 